\title{
Optics At The Arctic Circle, An Example Of Application-Oriented Research Generating New Industrial Activities
}

Jorma Lammasniemi, Risto Myllyla, Tapio Hannula

Jorma Lammasniemi, Risto Myllyla, Tapio Hannula, "Optics At The Arctic Circle, An Example Of Application-Oriented Research Generating New Industrial Activities," Proc. SPIE 0978, 1988 Intl Conf on Education in Optics, (27 April 1989); doi: 10.1117/12.948596

Event: 32nd Annual International Technical Symposium on Optical and United States 
Optics at the Arctic Circle, an example of application-oriented research generating new industrial activities

Jorma Lammasniemi, Risto Myllylä and Tapio Hannula

Technical Research Centre of Finland, Electronics laboratory P.0.Box 181, SF-90101 Oulu, Finland

\begin{abstract}
This paper discusses research/industry interaction in application-oriented research groups specializing in the development of optoelectronic instruments and measurement methods. The research groups are working in Oulu, a city in Northern Finland, in an industrial environment consisting originally of pulp and paper industries together with metalworking and engineering industries. These established industrial areas are active in adopting new technologies for automation and process renewal. Furthermore, new emerging businesses are being generated through pilot installations and new product ideas created by research groups. The technologies considered are optical and infrared process analyzers, semiconductor laser-based dimension measurements and optoelectronic hybrid module fabrication. Examples of new products and enterprises employing these technologies are given. Additional skills and education especially in miniature optics and related constructions, are considered important for the future.
\end{abstract}

\title{
1. INTRODUCTION
}

Although it is true that the optical properties of ice and snow have been studied by the scientific community in Oulu, Northern Finland $/ 1 /$, the aim of this paper is not to concentrate on optical equipment in an arctic environment but merely to provide an insight into application-oriented research and education in a small country with a specialized industrial background. The main questions raised are how the rapid development of optical and optoelectronic technologies can be used in the most beneficial way by existing industry and for industrial renewal and how research and education should be organized to fulfil these goals.

Finland is one of the Nordic countries (together with Denmark, Iceland, Norway, Sweden), and has a population of slightly less than 5 million. Its industrial background lies in pulp and paper together with the metalworking and engineering industries, reflecting the structure of natural resources. These areas still represent over $50 \%$ of the total value of industrial production and are nowadays characterized by intense activity in the adopting of new technologies and modernization. Machinery, operational skills and productivity in the wood processing industry in particular are on the highest international level, reflecting competition from countries with lower material and labour costs. In spite of the strong position of the basic industries, the industrial structure has been widening. Finnish exports of Hi-Tech products, which to a large extent consist of engineering, electrotechnical and chemical products, have doubled during the 1980's, although they still represent less than $10 \%$ of Finland's total exports $/ 2 /$.

Finland has no very remarkable history in the field of optics, but like electronics, optics and optoelectronics have already shown their potential in the renewal of instrumentation and automation in the old key industrial areas. To continue the analogy with the history of the electronics industry, several new small innovative companies have been started based on an assisting role in the old industries, and these can be expected to grow and generate their own independent areas of business.

Research into optics in Finland has earlier been carried out by some groups in university departments of physics, but quite recently someme new research projects have been started up, indicating the rapid increase in industrial interest in optoelectronics. These projects are Photonics (1984-86, 7 MFIM, 20 Man-years), Optoelectronics (1987-89, 10 MFIM, 30 Man-years) and Microelectronics (1987-90, 120 MFIM total including 40 MFIM, 80 Man-years, on optoelectronics). All these projects have their starting point in electronic engineering, which is now entering into the field of optoelectronic components and applications. Much of the content has been directed towards materials and basic research, but the application and instrument design research is now gaining ground. The research topics include optical and infrared materials and components, integrated optics, packaging, and the reliability of optoelectronic devices and the development of sensors, instruments and analyzers.

Oulu, a city of about 100000 people situated a mere 1.6 degrees south of the Arctic circle, is the home of the Electronics Laboratory of the Technical Research Centre of Finland (VTT) and of the University of Oulu, with 7500 students. Significant work is being done in optoelectronics at both VTT and the University. Recently new plans for further development in research and education have been created. The scope of this paper is to review current research and future plans and to analyze the progress made in industry/research interaction.

\section{THE STARTING POINT}

Based on the background described above the development of optical and optoelectronic equipment in Oulu was initiated about ten years ago by designers with an electronic engineering background. In the first place the goal was to develop sensors and instrumentation for the automation of basic domestic industries. At the 
beginning the optical part of the equipment was mostly fairly simple and the electronic and other parts dominated the design, reflecting the skills and technology available.

As the potential of optics and optoelectronics was proved and new promising prospects for technological development became evident, training and research activities was intensified. The optical designs became more sophisticated and the products were aimed at world markets.

Today the optoelectronics research group at the Electronics Laboratory of the Technical Research Centre of Finland has 25 members and the University team 15. No engineers specializing solely in optics have been educated so far, but the emphasis throughout has been kept on electronic engineering with additional skills in optics. Several courses have been arranged for the continuing education of engineers from industry and the various research groups. Instead of basic research, this research and teaching has been application and equipment design-oriented. The national research investments and programmes have supported this development, aithough much of their content has been directed towards materials and basic research.

The present research covers infrared and optical analyzer technologies, including studies on radiation, scattering and propagation phenomena in materials $/ 1,3,4 /$. Additionally, several industrial sensors have been developed, mostly employing fibre optics /5/. Another important research area has been the development of fast time-of-flight measurement of techniques for semiconductor laser pulses and related 1D and $3 \mathrm{D}$ range measurement applications $/ 6,7 /$.

\section{RESEARCH/INDUSTRY INTERACTION}

The transfer of important technology from government laboratories and universities to private sector entrepreneurs has been greatly facilitated since the change in the government's university policy made this activity a primary mission. Researchers are seeing their technologies put to work in the creation of new products, new markets and new jobs. The optoelectronics research groups in Oulu have established a growing number of industrial contacts through their efforts to find markets for new technologies. Two working methods have been used: a) expert assistance to develop commercial products for existing companies, b) encouragement of researchers to build up new companies. A suitable starting up environment for most of the new companies has been found in the Oulu Technology Park situated close to the University.

A list of examples of such new research-based industrial activities is presented below.

\subsection{Optics renewing established industries}

Kajaani Electronics Ltd. Kajaani Electronics Ltd, a member of the Valmet Automation Group, is an example of a Finnish company with a background in the pulp and paper industry which has more recently entered a new area of business by selling measuring instruments and its process control knowhow to this branch of industry. The company has been engaged in innovative application work to develop optical measurement methods in particular.

Kajaani Electronics produce principally instruments for mechanical pulping, pulp bleaching, stock preparation and paper machine wet end processes. Due to rising production costs and quality requirements, the pulp and paper industry is demanding more efficient and more accurate process control. This means a higher degree of automation based on reliable measurements.

Most of the R\&D work of Kajaani Electronics has been done by the company's own research group /9, 10/, but expert assistance from university researchers and postgraduate training courses have been in active use. Recent instruments developed which employ optics include the following:

- a pulp brightness sensor that measures the brightness in the process pipe, giving continuous information on the course of the bleaching process. It is based on the measurement of scattered light at four wavelengths using fibre optics. A central unit calculates the brightness values (Fig. 1).

- an optical consistency transmitter for the measurement of low consistency (1 to $1.5 \%$ in pulp suspensions. The operation of this device is based on light polarizing techniques. There is also a model to measure ultra-low consistencies (below $0.2 \%$ ).

- an automatic system for the measurement of characteristics of wood fibres. Its operation is based on laser technology and the device is able to analyze about one hundred fibres per second with an overall length resolution of $50 \mu \mathrm{m}$.

SLO Instruments. SLO Instruments is a group within the Nokia Corporation with about ten years history in the development of water oil content analyzers, especially for tanker ships (Fig. 2). The company has its background in electric maintenance and components for maintenance work. The new instruments have been developed in close cooperation with the Electronics Laboratory of the Technical Research Centre of Finland in Oulu. The third partner responsible for water sampling and treatment was AEG in Germany.

One highly essential topic in this work has been the application custom-designed multichannel IR detectors which were earlier typically used only in space and military context. This technology is one of the key areas of the Research Centre /3, 4/. The instrument is based on the absorption of infrared radiation in the $3.4 \mu \mathrm{m}$ wavelength band. By using several channels it is possible to achieve non-sensitivity to disturbances normally 
present such as particles of rust, mud and sand. In addition to on-board use, the analyzers are also being adopted in land-based applications. Pilot installations have been carried out in the control of cooling water in power stations and of waste water in pulp-processing plants.

Rautaruukki 0y. Rautaruukki is mainly a steel corporation but is actively looking for applications for new technologies, e.g. to make its processes more efficient. Many manual measurements are still performed in its steel works because of the lack of suitable sensors. The objects are of ten hot and non-contact measurements are needed. On the other hand, automation of the measurements would be important to ensure higher quality, higher productivity and less expenditure of labour. Distance measurements have many applications in steel works, e.g. the measurement of the level of molten steel in the mould of a continuous casting line, determination of the shapes and dimensions of hot objects, or measurement of the thickness and quality of the sheathing of the converter.

As an example of the last application, an instrument for converter shealth measurement has been developed in collaboratorion with the University research group (Fig. 3) /7/. The instrument is based on the laser rangefinder principle measuring the transit time required for a very short semiconductor laser pulse to reach the optically visible target and for the reflected pulse to return to a receiver. The instrument can be installed in the roughest industrial environments in the iron and steel industry. It is mainly intended for measuring the thickness of the fire-brick sheathing of a converter, although it can easily be employed for distance measurements with respect to other passive objects. The main problems in this application are the extremely high temperatures $\left(1200-1400^{\circ} \mathrm{C}\right)$, the low reflectivity of the sheathing and the relatively long measurement distance $(10-20 \mathrm{~m})$. A $2 \mathrm{~mm}$ distance measurement resolution is achieved using an averaging time of 1 second.

\subsection{New companies}

Since many of the inventions coming from university and research laboratories are best suited for development by small enterprises, university and Research Centre policy has been to encourage employees who make such inventions to consider starting their own companies when no existing company seems to be able to take advantage of the invention. To help the new entrepreneur, inventions have been developed for commercial production in collaboration with the research laboratory and using its facilities. The Oulu Technology Park nearby is also offers assistance in the practical issues of starting a company. Some examples in the field of optoelectronics are given below.

Noptel Ky. Noptel was founded in 1982 by a research group at the Electronics Laboratory to exploit the research and development work in optoelectronics being carried out at the University of Oulu. It has been associated with the Oulu Technology Park from the outset. Noptel has specialized in measurement applications based on semiconductor light sources and detectors, e.g. laser radar and marksmen's training systems (Fig. 4) $18 /$.

The training system includes a laser transmitter, optical target and personal computer. The laser transmitter emits a continuous narrow beam of light during the sighting and shooting process and enables recording of the trajectory of the hit on an optical target. The recorded information on the sighting and shooting process can be analyzed by computer and displayed on a monitor or printed on paper. These graphs give information on the whole shooting process for coaches and marksmen. The system has been successfully used in many countries since 1985 .

Prometrics Oy. Prometrics was founded in 1985 by a researcher at the Electronics Laboratory of the Technical Research Centre of Finland and a colleague from the University of Oulu. Prometrics has developed a unique system for accuracy control in large-scale assembly. The key element of the system is a laser coordinate measuring device which is based on laser rangefinder techniques developed over many years in academic research groups. Similar basic knowhow is used in the Rautaruukki steel plant instruments described above.

The specific product of the Prometrics company comprises a work station for processing accuracy data, a data acquisition unit for gathering a wide range of measurement data and the coordinate measuring device (Fig. 5) for measurements on large-sized three-dimensional structures. The user is able to see at once if a measurement deviates from the original design value and is given a reminder that the tolerance limits have been exceeded. The results are presented in graphic form at the work station and the data stored in the database for future reference. The system is especially suited for shipbuilding.

Inoptics Ltd. Inoptics Ltd is a new technology service-oriented company in optoelectronics. Beginning from early 1980's the Oulu research groups have been engaged in several projects to develop IR instruments for industrial processes. The common denominator in these projects has been the need for high performance detector and signal preprosessor modules, which should be as compact as possible and tolerate harsh industrial environment. These requirements led to packaging technologies used earlier only in military or corresponding applications. The availability of technology services and module fabrication was insufficient and the development phase was tedious and time-consuming. Therefore a three-year technology project was launched in 1984 to develop facilities and skills for constructing hybrid detector/receiver modules (Fig. 6) /3/.

The project included technologies for the packaging and hermetic sealing of modules with optical, optoelectronic and signal processing components. The project was completed in early 1988. Because of the 
promising business prospects and technological results, some industrial partners in the joint project decided to start a company, Inoptics Ltd., to commercialize the results.

The aim of Inoptics is to act as a specialized service-oriented company of fering hybrid modules and related consulting and development services. The first customers were Finnish companies, including in-house production for some of the owners, but the main markets proved to be in the Nordic countries in the first phase and later on more widely throughout the world.

\section{EDUCATIONAL AND RESEARCH AIMS FOR THE 1990'S}

The University of Oulu consists of five faculties, and the Electronics Laboratory is part of the Department of Electrical Engineering within the Faculty of Technology. The Department, which was founded in 1965, trains graduates for the degree of Diploma in Engineering, roughly equivalent to the American M.Sc. Post-graduate studies lead to the degrees of Licentiate in Technology and Doctor of Technology. 120 students are accepted annually.

Teaching and research in the Electronics Laboratory are concentrated upon the development and application of professional electronics for circuit and equipment design, one of the topics being applied optoelectronics. Two half-year courses are given in optoelectronics at the moment. The first includes fundamentals of the use of visible and infrared radiation in applications for measurement techniques and communication and the second course comprises technical and physical optics. Special courses are given for continuing education. About 10 students a year specialize in optoelectronics.

The Laboratory's teaching policy also assumes that the integration and combination of technologies will be important. A central message given to the students is that in future they must be able to fuse many technologies to create new products or improve the functioning of traditional ones. These technological families include microelectronics, optoelectronics, functional materials and mechanical engineering.

Teaching in the future is intended to continue to be based on electronic engineering, but the role of optics and optoelectronics will be strengthened. In view of the industrial profile and the needs described above, the weight will be on applications, equipment design and construction skills. continuing education of engineers from industry will also be essential. Topics such as optics for industrial instruments, infrared optics, new optoelectronic components and micro-optics are constantly being requested.

Future research will be aimed at introducing and applying new technologies for the manufacture of optical components especially in miniature optics. Additional efforts should be directed towards hybrid module building, CAD in optics, and sensor and analyzer development.

It is seen that both of the main research areas described above, i.e. the IR analyzer and laser rangefinder technologies carry a potential for many additional spin-off applications. The number of feasible products is greatly dependent on environmental tolerances and the compactness of the design.

The research programme is aimed at pointing out the strategic relevance of the fusion of the basic technological families and their industrial impacts. This is not directed towards any single industry but, like microelectronics, influences a broad range of industries and can be called a generic or basic technology.

\section{CONCLUSIONS}

It has been shown that optoelectronics has a high potential for the development of new innovative sensors and measuring instruments. Application-oriented research can successfully be used for the benefit of the process and manufacturing industries. Also, the example of Oulu, a city in Northern Finland, has shown that appropriate teaching and research in optics together with good skills in the design of electronic equipment can offer possibilities for the renewal of established industries and the creation of new businesses.

It is believed that for a small country without any notable history in optics, application-oriented research is greatly preferable to materials and basic research. Good skills in equipment construction and other practical forms of knowledge are to be favoured.

\section{REFERENCES}

1. T. Hyvărinen and J. Lammasniemi, "Infrared measurement of free-water content and grain size of snow," Opt. Eng. 26(4), 342-348 (1987).

2. Reviews of national science and technology policy: Finland. OECD publications, France (1987), ISBN 9264-12928-6. $153 \mathrm{p}$.

3. P. Niemelä, "Infrared detectors for industrial process analyzers," Proc. of the conference on Infrared technology and applications (London June 1988), Sira Ltd. To be published in Proc. SPIE 918.

4. P. Niemelä, J. Jaatinen, "On-line analyzer for monitoring trace amounts of oil in turbid waters," Proc. SPIE 590, Infrared Technology and Applications, 311-315 (1985).

5. H. Kopola, "Intensity-modulated fibre-optic sensors for robotic, medical and industrial applications," Acta Universitas Ouluensis, Series C Technica 45. ISBN 951-42-2584 (1988), 105 p.

6. I. Moring, H. Ailisto, T. Heikkinen, A. Kilpelä, R. Myllylä, M. Pietikăinen, "Acquisition and processing of range data using a laser scanner-based 3D-vision system," Proc. SPIE 850, 174-182 (1988). 
7. K. Măattä, J. Kostamovaara, R. Myllylä, "A laser rangefinder for hot surface profiling measurement," Laser Technology in Industry, 6-8 June (1988), Porto, Portugal. 8 p. (to be published).

8. R. Myllyla, R. Ahola, H. Kopola, J. Kostamovaara, M. Sarjala, "A laser based method for marksmanship analysis and training," The Second European Shooting Conferation Scientific Congress, Osijek, Yogoslavia (1988), pp. 568-578.

9. L. Paavilainen, J. Tornberg, K. Lehmikangas, "Determination of the weight ratio of pulp components in a blend - Quantitative fiber analysis," Paperi ja puu - Paper and Timber 1(1988), pp. 57-60.

10. H. Kortelainen, "Continuous retention monitoring system as a tool for the optimization of wet end operation," 1988 Papermakers' Conference/TAPPI. Atlanta, March 1988. 

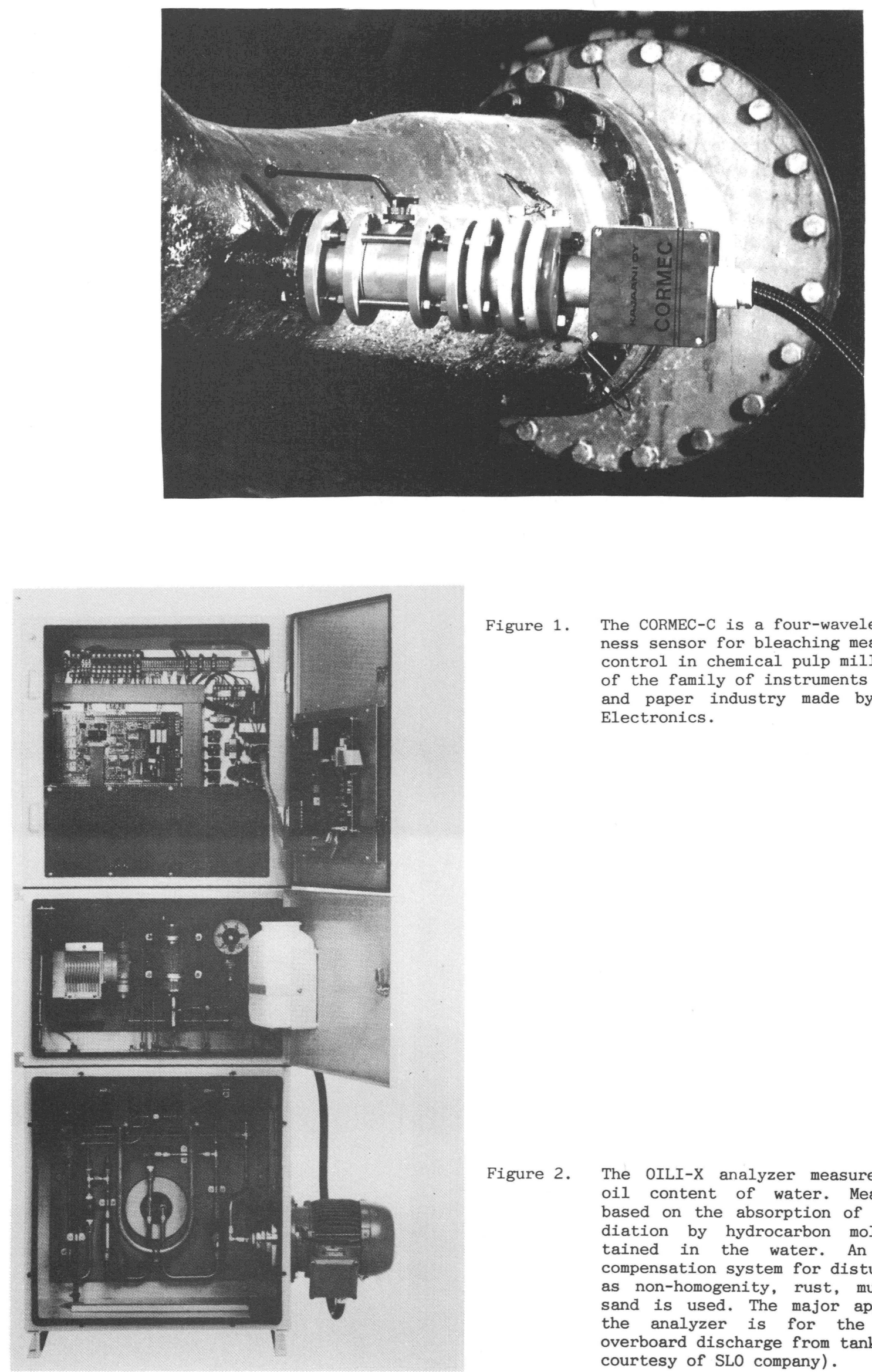

Figure 1. The CORMEC-C is a four-wavelength brightness sensor for bleaching measurement and control in chemical pulp mills. It is one of the family of instruments for the pulp and paper industry made by Kajaani $\mathrm{Oy}$ Electronics.

Figure 2. The OILI-X analyzer measures the total oil content of water. Measurement is based on the absorption of infrared radiation by hydrocarbon molecules contained in the water. An intelligent compensation system for disturbances such as non-homogenity, rust, mud, silt and sand is used. The major application of the analyzer is for the control of overboard discharge from tanker ships (by courtesy of SLO company). 


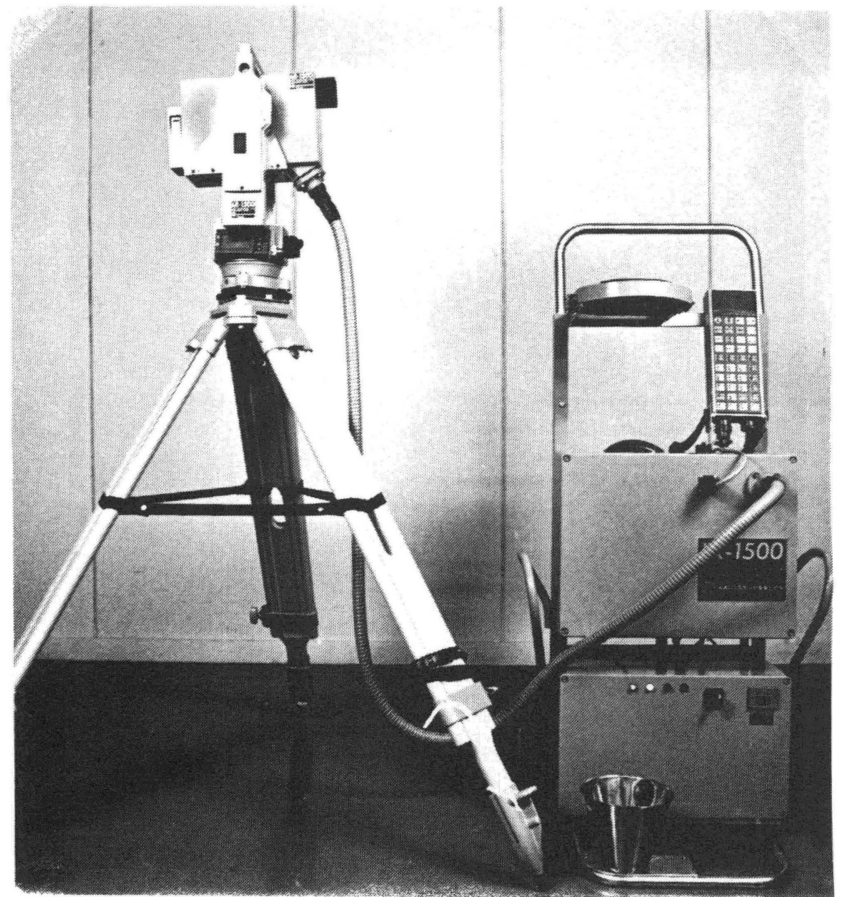

Figure 3. A laser rangefinder for hot surface profiling measurements. The rangefinder consists of an optomechanical measuring head, electronics unit and computer. The resolution achieved is a few millimetres with a measurement time less than 1 second per measurement point. The system accuracy is better than $1 \mathrm{~cm}$ in a range of 6 to 17 metres (by courtesy of Rautaruukki Oy).

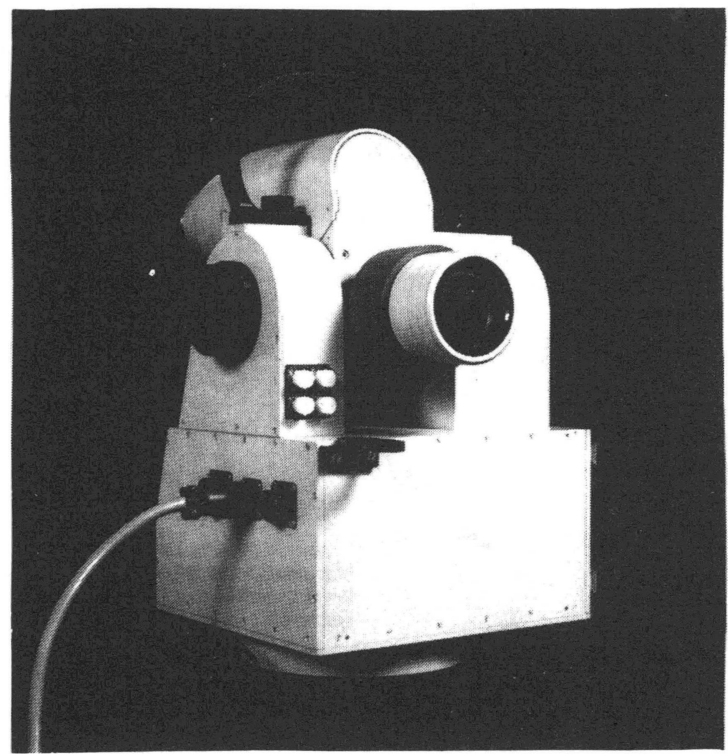

Figure 5. A laser coordinate measuring device for measurements of large-sized three-dimensional objects. The device is used together with a computer workstation to compare measured dimensions with design values. The system is especially suited for shipbuilding (by courtesy of Prometrics Oy).

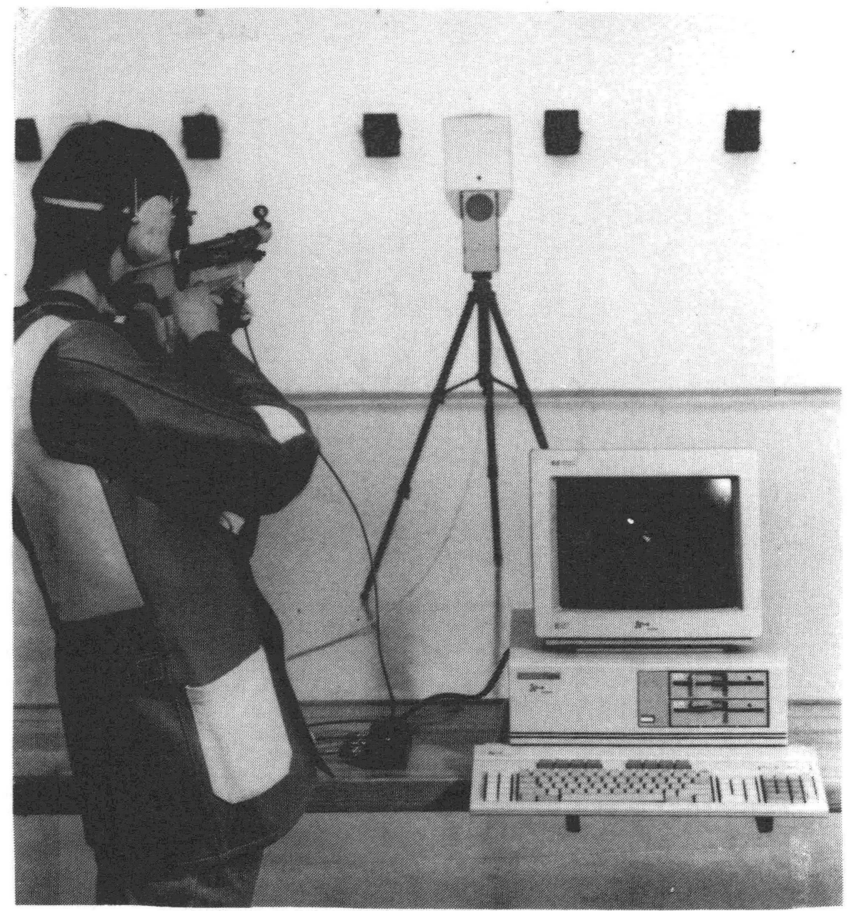

Figure 4. Laser training equipment for marksmen. The transmitter emits a continuous light beam during sighting and shooting and enables recording of the sighting trajectory and triggering event. The system can be attached to, and easily calibrated for various weapons (by courtesy of Noptel Ky) .

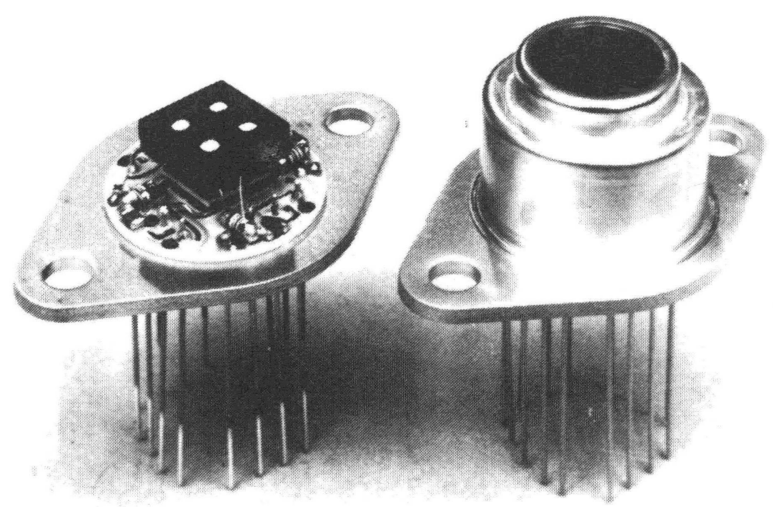

Figure 6. A four-channel detector assembly for an industrial process analyzer. The module contains all the supporting functions needed by photoconductive lead-salt detectors, including interference filters, TE cooler, temperature sensor and hybrid preamplifiers (by courtesy of Inoptics Inc.). 